\title{
LAS FINANZAS INTERNACIONALES Y EL RIESGO DE TIPO DE CAMBIO
}

\author{
INTERNATIONAL FINANCE AND THE RISK OF EXCHANGE RATE
}

\section{Emilio Garcia Villegas}

Docente Asociado de la Facultad de Ciencias Contables, UNMSM

[Recepción: Enero de 2010 / Conformidad: Marzo de 2010]

\section{RESUMEN}

Tres grandes aspectos se resaltan en las finanzas internacionales a) los riesgos internacionales b) oportunidades internacionales y c) las imperfecciones del mercado.

En los riesgos internacionales los riesgos financieros cobran relevancia y dentro de ellos el riesgo de tipo de cambio que durante los últimos años debido a las constantes fluctuaciones de monedas como el dólar americano, el yen japonés, la libra esterlina y el euro han impactado en la situación económica y financiera de las empresas.

En los últimos años ha cobrado real importancia fortalecer a la alta dirección en la Gestión de Riesgos. Las organizaciones enfrentan diversos tipos de riesgos, ya sean riesgos propios del negocio en que se desenvuelven, financieros y operacionales, como riesgos ajenos a su operación, sociales, ambientales, y éticos, los cuales son cada día más globales y complejos producto del entorno dinámico en que se encuentran insertas. Por ello las organizaciones han debido ser hábiles en identificar y gestionar estos riesgos para encausarlos a niveles aceptables, con el fin que sean percibidos como oportunidades y no como amenazas.

Se ha intensificado considerablemente la exposición al riesgo de Instituciones Financieras, producto del aumento importante en el volumen de operaciones y la gran variedad de servicios que proporcionan. El riesgo es inherente al negocio financiero, razón por la cual es fundamental que las Instituciones

\begin{abstract}
Three major aspects are highlighted in international finance), international risks b) international opportunities and c) market imperfections.

International risk-financial risks become relevant and insids them the risk of exchange rate that during the last years due to constant fluctuations of currencies like the U.S. dollar, Japanese yen, pound sterling and the euro have impacted economic and financial situation of enterprises.

In recent years has been real important to strengthen the senior management in Risk Management. Organizations face a variety of risks and hazards of business are affecting the development, financial and operational, and beyond their operating risks, social, environmental, and ethical issues, which are increasingly global and complex product of the dynamic environment they are embedded. Therefore organizations should have been working to identify and prosecute them manage these risks to acceptable levels, in order to be perceived as opportunities and not threats.

Has increased considerably the risk exposure of financial institutions as a result of the significant increase in trading volume and variety of services they provide. The risk is inherent in the financial business, which is why it is essential that financial institutions have adequate systems of internal control. It should establish a formal internal control system, whose main concern is focused on
\end{abstract}

* Magíster en Administración, Universidad del Pacífico. Contador Público Colegiado. Docente Asociado de la Facultad de Ciencias Contables, UNMSM. Gerente de Auditoría de Urbizagastegui y Asociados. E-mail: garciaemiliov@yahoo.es 
Financieras posean adecuados sistemas de control interno. Se debe establecer un sistema de control interno formal, cuya preocupación principal se encuentre orientada a la administración eficiente de los riesgos asociados a los negocios, en concordancia directa con los objetivos estratégicos empresariales. En caso de prescindir de este tipo de sistema, podría poner en riesgo no sólo la continuidad de la organización, sino además el equilibrio y desarrollo del sector en el que se encuentre inserta.

El concepto de Gestión del Riesgo se compone de un proceso conjunto que es Evaluación del Riesgo y Control del Riesgo.

La evaluación de riesgos es un proceso enfocado a estimar el impacto de aquellos riesgos que puedan afectar el normal ejercicio de una entidad, recopilando la información necesaria para que la organización pueda tomar una decisión adecuada sobre la necesidad de adoptar medidas preventivas.

Palabras clave: Finanzas internacionales, gestión del riesgo, evaluación de riesgo, riesgo financiero, riesgo de tipo de cambio.

\section{INTRODUCCIÓN}

Tres grandes aspectos se resaltan en las finanzas internacionales a) los riesgos internacionales b) oportunidades internacionales y c) las imperfecciones del mercado.

En los riesgos internacionales los riesgos financieros cobran relevancia y dentro de ellos el riesgo de tipo de cambio que durante los últimos años debido a las constantes fluctuaciones de monedas como el dólar americano, el yen japonés, la libra esterlina y el euro han impactado en la situación económica y financiera de las empresas.

En los últimos años ha cobrado real importancia fortalecer a la alta dirección en la Gestión de Riesgos. Las organizaciones enfrentan diversos tipos de riesgos, ya sean riesgos propios del negocio en que se desenvuelven, financieros y operacionales, como riesgos ajenos a su operación, sociales, am- efficient management of risks associated with doing business in direct accordance with strategic business goals. If without this type of system, could jeopardize not only the continuity of the organization, but also the balance and development of the sector in which it operates.

The concept of Risk Management consists of a joint process is Risk Assessment and Risk Control.

Risk evaluation is a process focused on estimating the impact of risks that could affect the normal performance of an entity collecting the information necessary to enable the organization to make an informed decision about the need for preventive measures.

Key words: International finance, risk management, risk assessment, financial risk, exchange rate.

bientales, y éticos, los cuales son cada día más globales y complejos producto del entorno dinámico en que se encuentran insertas. Por ello, las organizaciones han debido ser hábiles en identificar y gestionar estos riesgos para encausarlos a niveles aceptables, con el fin que sean percibidos como oportunidades y no como amenazas.

Se ha intensificado considerablemente la exposición al riesgo de instituciones financieras, producto del aumento importante en el volumen de operaciones y la gran variedad de servicios que proporcionan. El riesgo es inherente al negocio financiero, razón por la cual es fundamental que las Instituciones Financieras posean adecuados sistemas de control interno. Se debe establecer un sistema de control interno formal, cuya preocupación principal se encuentre orientada a la administración eficiente de los riesgos asociados a los negocios, en concordancia 
directa con los objetivos estratégicos empresariales. En caso de prescindir de este tipo de sistema, podría poner en riesgo no solo la continuidad de la organización, sino además el equilibrio y desarrollo del sector en el que se encuentre inserta.

El concepto de Gestión del Riesgo se compone de un proceso conjunto que es Evaluación del Riesgo y Control del Riesgo.

La evaluación de riesgos es un proceso enfocado a estimar el impacto de aquellos riesgos que puedan afectar el normal ejercicio de una entidad, recopilando la información necesaria para que la organización pueda tomar una decisión adecuada sobre la necesidad de adoptar medidas preventivas.

\section{GUÍAS DE DISCUSIÓN}

¿Por qué necesitamos estudiar finanzas internacionales?

¿Qué relación hay entre las finanzas internacionales y los riesgos financieros?

¿Están las empresas peruanas preparadas para operar a nivel internacional?

¿Estamos los contadores públicos preparados para registrar, analizar y gestionar las transacciones que realicen nuestras empresas a nivel internacional?

¿Es necesario que las empresas implementen mecanismos para coberturar sus riesgos financieros?

¿Son los forwards un instrumento adecuado para coberturar el riesgo de tipo de cambio?

\section{Las Finanzas Internacionales}

Las Finanzas internacionales son un área del conocimiento en la que participan las finanzas corporativas y la economía internacional, en ella se analizan los flujo de efectivo que se producen en las transacciones de las empresas multinacionales.

Las finanzas internacionales describen los aspectos monetarios de la economía internacional, se analiza la balanza de pagos, sus desequilibrios en la que la variable principal es el tipo de cambio.

Debido a la globalización de la economía es necesario que los ejecutivos de las empresas tengan una comprensión cabal de las finanzas internacionales para medir el impacto que puedan generar sobre sus empresas los cambios en el entorno financiero internacional, como una variación de la tasa de interés de la Reserva Federal de los Estados Unidos de norteamericana o una variación en el tipo de cambio del yuan.

La globalización financiera se ha incrementa significativamente en estos últimos años creando oportunidades, pero a la vez también riesgos que tienen que ser medidos $y$ gestionados adecuadamente.

Ahmada Rahnema considera tres dimensiones de las finanzas internacionales: 1) Riesgos Internacionales, 2) oportunidades internacionales, 3) imperfecciones del mercado.

\section{Riesgos Internacionales}

Las variaciones del tipo de cambio, de las tasas de interés y de los precios han motivado que la identificación, medición y gestión de los riesgos originados por estas fluctuaciones ocupen un papel importante en las finanzas internacionales. El dólar está sufriendo fluctuaciones constantes incidiendo para que el tipo de cambio del nuevo sol sea muy volátil. 


\section{Oportunidades Internacionales}

La internacionalización de las operaciones de la empresa le genera beneficios; al ampliar su crecimiento, le genera economías de escala, diversifica sus ventas, generando una mayor rentabilidad y reduciendo su riesgo a través de la diversificación de sus ventas.

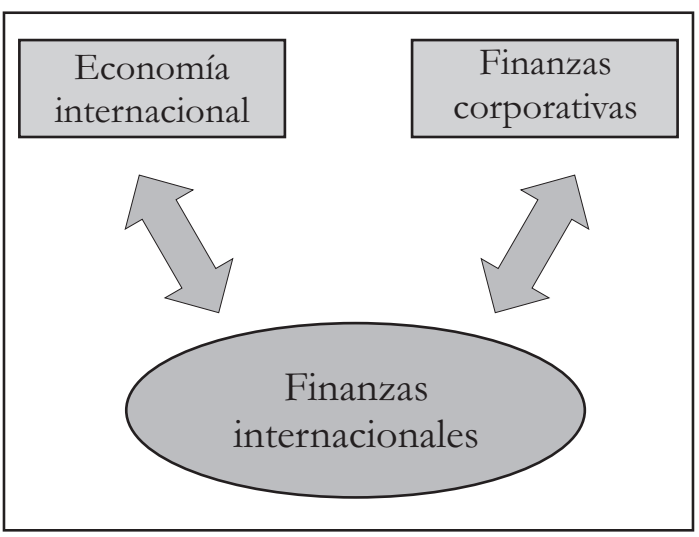

Figura N.o 1. Orígenes de las Finanzas Internacionales.

\section{Gestión de Riesgos Financieros}

\subsection{Gestión del riesgo}

La gestión integral de los riesgos es un proceso estructurado, consistente y continuo implementado a través de toda la organización para identificar, evaluar, medir y reportar amenazas y oportunidades que afectan el poder alcanzar el logro de sus objetivos.

La Gestión de riesgo también puede definirse como la identificación, medición y evaluación colectiva de todos los riesgos que afectan el valor de la entidad financiera, así como la definición e implementación de una estrategia en el negocio y en la operación para gestionar efectivamente esos riesgos.

\section{Imperfecciones del Mercado}

Las imperfecciones del mercado crean trabas y barreras en su buen funcionamiento, pero a la vez también generan oportunidades.

La imperfección en los mercados financieros globales es el causante de gran parte de las operaciones de financiación y derivados.

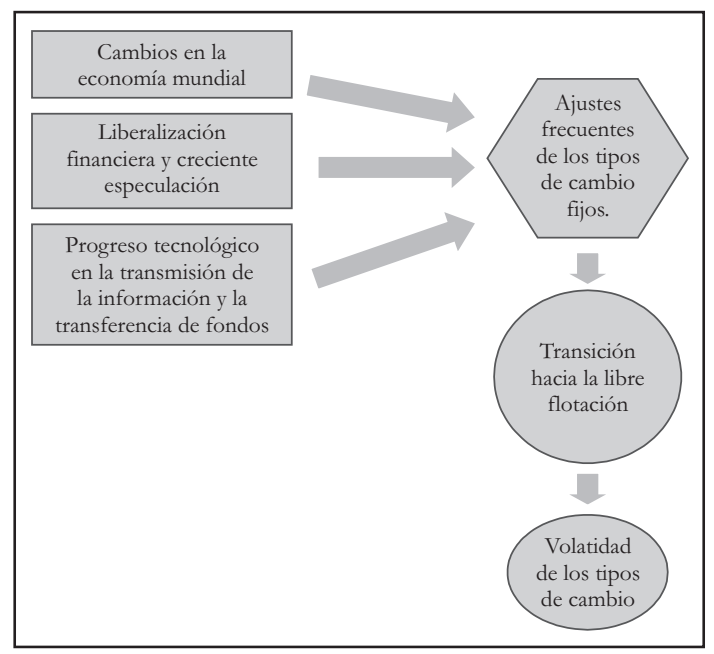

Figura N.o 2. Causas de la volatilidad de los tipos de cambio.

Para una Gestión de Riesgos Eficaz se debe buscar:

- Definir criterios de aceptación general de riesgos, de acuerdo a la actividad comercial de la entidad bancaria (matriz segmento, mercado, producto, canal)

- Uso de un mapa de riesgo para definir el área aceptable de exposición, el riesgo máximo aceptable (área de peligro) y el área no aceptable de exposición al riesgo.

- Relacionar el área máxima de exposición al riesgo con el capital que se desea arriesgar en forma global y por unidad estratégica de negocio.

- Monitoreo y medición de todas las categorías de riesgo que pueden impactar el valor del banco (en forma global, por unidad de negocio, por productos y procesos). 
- Definir el tipo de pérdida que se desea estimar, su horizonte temporal, metodológica o modelo.

- Diseñar mecanismos de cobertura de los riesgos, con una visión integral y comprensiva del negocio.

- Definir y estimar medidas de desempeño ajustadas por riesgo.

\subsection{Riesgo}

Podemos definir el riesgo como a la incertidumbre de que ocurra un hecho que pueda afectar negativamente a la capacidad de una empresa para obtener sus objetivos económicos financieros, operacionales y estratégicos.

\subsubsection{Clasificación de riesgos}

Existen diferentes clasificaciones de riesgo, hemos tomado la clasificación presentada por Ahmad Rahnema (1) que considera tres grandes grupos de riesgos: financiero, operacional y estratégico.

- Riesgo operacional. Se refiere a las pérdidas potenciales resultantes de procesos inadecuados, fallas administrativas $y$ controles defectuosos, fraude o error humano.

- Riesgo Estratégico. Surge pos factores del entorno que puedan afectar adversamente la capacidad de la empresa de lograr sus objetivos estratégicos.

\section{RIESGO FINANCIERO}

El riesgo Financiero es un riesgo inherente a la realización de operaciones financieras debido a la incertidumbre que existe al momento de ser realizadas.

Grafico N.o 3. Clasificación de riesgos

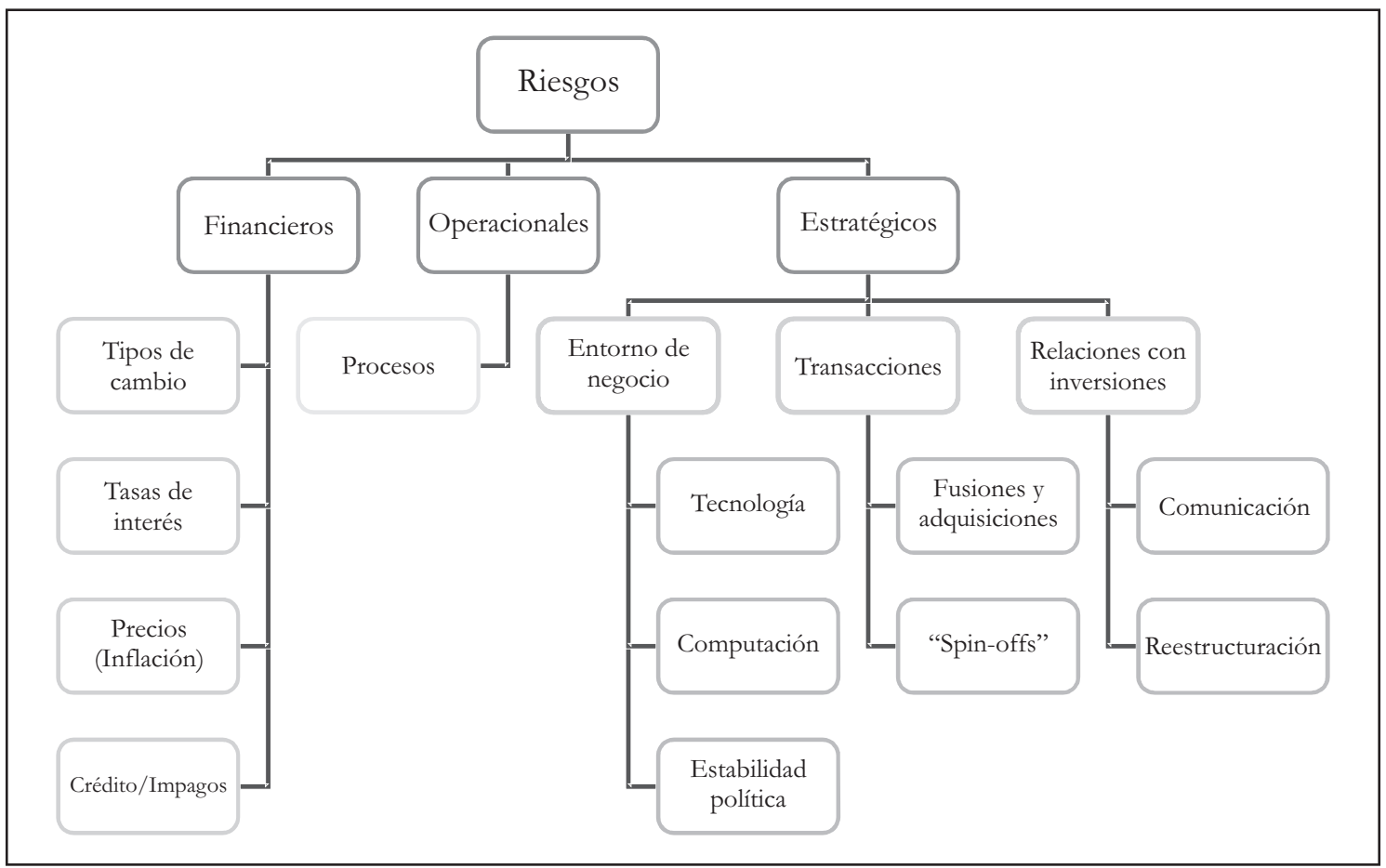

Fuente: Ahmad Rahnema Finanzas Internacionales. 
Podemos también decir que es el riesgo de no estar en condiciones de cubrir los costos financieros, por esto su análisis se pude determinar por el grado de apalancamiento financiero que posea la organización en un momento determinado, el cual engloba consecuencias adversas que puedan producirse por una alteración cuantitativa o cualitativa en los ingresos presupuestarios, recogiendo las disminuciones efectivas de recursos financieros mantenidos en ejercicios presupuestarios previos, así como el desaprovechamiento de iniciativas que faciliten el incremento o diversificación de las fuentes de financiación.

Además, se puede ver cómo el riesgo de pérdidas en posiciones dentro y fuera del balance proveniente de movimientos adversos en los precios de mercado.

Por todo lo anterior, podemos decir que el riesgo financiero está compuesto por:

1. Riesgo de tasa de interés

2. Riesgo cambiario

3. Riesgo de liquidez

\subsection{Riesgo de tasa de interés}

Es aquel que surge del descalce entre activos y pasivos que se encuentran sujetos a un cambio en la tasa de interés en un periodo específico y en una moneda específica. Existen mecanismos de cobertura de este riesgo a través de instrumentos financieros derivados.

\subsection{Riesgo Cambiario}

Es aquel que surge de la variación en las paridades de mercado de las distintas monedas en que un Banco mantiene posiciones. Estas posiciones pueden ser largas (activos mayores que pasivos) o cortas (pasivos mayores que activos). Existen diferentes instrumentos de cobertura, pero los más significativos desde el punto de vista financiero son los seguros de cambio y los productos derivados.

\subsection{Riesgo de liquidez}

Es aquel que surge de la posibilidad que el Banco sea incapaz de cerrar de forma rápida sus posiciones, en cantidades suficientes $y$ a un precio razonable, incurriendo en efectos financieros adversos. Se puede considerar este riesgo, como el derivado de los desfases entre el grado de exigibilidad de las operaciones pasivas ligadas a la inversión y el grado de realización de los activos. Los problemas de liquidez no coyunturales en la banca son debidos esencialmente a una ineficiente transformación de activos, que es, por otra parte, la función primordial de una industria.

En las entidades bancarias el riesgo de liquidez es capital, debiéndose someter a complejos mecanismos de planificación y control. En el funcionamiento básico del sistema bancario opera la denominada "regla de la compensación”, mediante la cual se supone que la retirada de depósitos por parte de los clientes se compensa con la captación de nuevos depósitos y clientes.

\section{MARCO REGULATORIO DEL RIESGO FINANCIERO}

\subsection{Internacional}

Existen diferente estándares internacionales sobre como deben abordar las entidades la gestión de Riesgos financieros, entre ellos se tiene: Grupo de los treinta, el Grupo sobre Políticas para Instrumentos Financieros Derivados y el Comité de Basilea o Banco de Pagos Internacionales. 


\section{Comité de Basilea}

Fue fundada en 1930, tiene su sede en Basilea es un foro de debate sobre la supervisión bancaria, cuyo fin es garantizar una supervisión eficaz de las entidades bancarias en todo el mundo. Las recomendaciones del Comité no son normas internacionales o acuerdos entre países miembros que tengan fuerza de obligación por sí mismas. Sin embargo, a pesar de la falta de poderes formales, la doctrina elaborada tiene una influencia considerable.

Basilea I: Acuerdo de Capitales Basilea (ACB)

El 15 de julio de 1988, el Comité publica el ACB o Basilea 1 que exige que los bancos mantengan, como grupo bancario consolidado, un nivel mínimo de capital que permita absorber las pérdidas que pueden provocar los riesgos que asumen (riesgo de crédito), sin que la entidad quiebre.

Basilea II: Nuevo Acuerdo de Capital de Basilea

Como consecuencia de la coyuntura internacional de consolidación de actividades financieras en conglomerado liderado por una sociedad controladora, la actividad bancaria, las practicas de gestión de riesgos, los enfoques de supervisión y los mercados financieroshan experimentado significativas transformaciones que restan eficacia al ACB. Debido a estos aspectos se ha vuelto el establecimiento de medidas que ayuden a fortalecer los procesos de supervisión bancaria.

En el mes de enero del año 2001 surgió una nueva propuesta del Comité de Supervisión Bancaria sobre adecuación de capital conocida como Basilea II y que pretende ser una reforma de la regulación de la solvencia bancaria en el ámbito internacional.

El nuevo acuerdo de capital intenta mejorar la seguridad y solvencia del sistema fi- nanciero, presentándose como una norma de adecuación del capital más sensible al riesgo de las operaciones bancarias, en las que se ofrecen incentivos a las entidades para que mejoren su capacidad para gestionar y controlar estos riesgos. El acuerdo tomó como pilar los requisitos de capital mínimo.

\subsection{Regulación peruana}

La normativa peruana respecto a la regulación de los riesgos financieros establecidos por La SBS , derivan del Acuerdo de Capital.

El Art. 184 de la Ley del Sistema Financiero establece la conformación del patrimonio efectivo y el Art. 186, el Patrimonio efectivo a destinado a cubrir Riesgos de Mercado

En el Art. 188, se establecen las categorías de activos y los factores de ponderación de riesgo de cada activo:

Categoría I: Activos con Riesgo 0\%

Categoría II: Activos con Riesgo 10\%

Categoría III: Activos Riesgo 20\%

Categoría IV: Activos con Riesgo $50 \%$

Categoría V: Activos con Riesgo 100\%

Articulo 199 Límite Global.

El monto de los activos y créditos contingentes ponderados por Riesgo Crediticio en moneda nacional o extranjera, no pueden exceder de once veces su patrimonio efectivo destinado a cubrir su riesgo de mercado.

\section{Gestión integral de riesgos}

Mediante la Resolución N. ${ }^{\circ}$ 37-2008 del 10 de enero del 2008, la Superintendencia de Banca y Seguros aprueba el Reglamento de la Gestión Integral de Riesgos ,aplicable para las entidades del sistema financiero.

En la Resolución se considera que "La Gestión Integral de Riesgos es un proceso, efectuado por el Directorio, la Gerencia y 
el personal aplicado en toda la empresa y en la definición de su estrategia, diseñado para identificar potenciales eventos que pueden afectarla, gestionarlos de acuerdo a su apetito por el riesgo y proveer una seguridad razonable en el logro de sus objetivos".

Se deben considerar los siguientes elementos:

a) Ambiente interno. Que comprende, entre otros, los valores éticos, la idoneidad técnica y moral de sus funcionarios; la estructura organizacional; y las condiciones para la asignación de autoridad y responsabilidades.

b) Establecimiento de objetivos. Proceso por el que se determinan los objetivos empresariales, los cuales deben encontrarse alineados a la visión y misión de la empresa, y ser compatibles con la tolerancia al riesgo y el grado de exposición al riesgo aceptado.

c) Identificación de riesgos. Proceso por el que se identifican los riesgos internos y externos que pueden tener un impacto negativo sobre los objetivos de la empresa.

d) Evaluación de riesgos. Proceso por el que se evalúa el riesgo de una empresa, actividad, conjunto de actividades, área, portafolio, producto o servicio; mediante técnicas cualitativas, cuantitativas o una combinación de ambas.

e) Tratamiento. Proceso por el que se opta por aceptar el riesgo, disminuir la probabilidad de ocurrencia, disminuir el impacto, transferirlo total o parcialmente, evitarlo, o una combinación de las medidas anteriores, de acuerdo al nivel de tolerancia al riesgo definido.

f) Actividades de control. Proceso que busca asegurar que las políticas, estándares, límites y procedimientos para el tratamiento de riesgos son apropiadamente tomados y/o ejecutados. g) Información y comunicación. Proceso por el que se genera y transmite información apropiada y oportuna a la dirección, la gerencia, el personal, así como a interesados externos tales como clientes, proveedores, accionistas y reguladores.

h) Monitoreo. Proceso que consiste en la evaluación del adecuado funcionamiento de la Gestión Integral de Riesgos y la implementación de las modificaciones que sean requeridas.

Se consideran los siguientes tipos de riesgos:

a) Riesgo de crédito. La posibilidad de pérdidas por la imposibilidad o falta de voluntad de los deudores o contrapartes, o terceros obligados para cumplir completamente sus obligaciones contractuales registradas dentro o fuera del balance general.

b) Riesgo estratégico. La posibilidad de pérdidas por decisiones de alto nivel asociadas a la creación de ventajas competitivas sostenibles. Se encuentra relacionado a fallas o debilidades en el análisis del mercado, tendencias e incertidumbre del entorno, competencias claves de la empresa y en el proceso de generación e innovación de valor.

c) Riesgo de liquidez. La posibilidad de pérdidas por incumplir con los requerimientos de financiamiento y de aplicación de fondos que surgen de los descalces de flujos de efectivo, así como por no poder cerrar rápidamente posiciones abiertas, en la cantidad suficiente y a un precio razonable.

d) Riesgo de mercado. La posibilidad de pérdidas en posiciones dentro y fuera de balance derivadas de fluctuaciones en los precios de mercado.

e) Riesgo operacional. La posibilidad de pérdidas debido a procesos inadecuados, 
fallas del personal, de la tecnología de información, o eventos externos. Esta definición incluye el riesgo legal, pero excluye el riesgo estratégico y de reputación.

f) Riesgo de seguro. La posibilidad de pérdidas por las bases técnicas o actuariales empleadas en el cálculo de las primas y de las reservas técnicas de los seguros, insuficiencia de la cobertura de reaseguros, así como el aumento inesperado de los gastos y de la distribución en el tiempo de los siniestros. Se le conoce también como riesgo técnico.

g) Riesgo de reputación. La posibilidad de pérdidas por la disminución en la confianza en la integridad de la institución que surge cuando el buen nombre de la empresa es afectado. El riesgo de reputación puede presentarse a partir de otros riesgos inherentes en las actividades de una organización.

\section{GESTIÓN DEL RIESGO FINANCIERO}

La gestión del riesgo debe seguir una secuencia lógica expresada en las siguientes etapas :

1. Identificación de activos y pasivos cuyo valor está sujeto a variación, en el cual se tiene que precisar las casusas de la variación.

2. Medición del riesgo, intentando una cuantificación de la posible variación del mismo.

3. Establecer los objetivos de gestión del riesgo.

4. Selección de instrumentos y determinación de las estrategias a utilizar en función de los mismos.

\subsection{Las estrategias de cobertura}

La cobertura es un concepto que está vinculado a la gestión del riesgo y consiste en la toma de posiciones que evolucionan en forma opuesta a la del activo expuesta al riesgo . Mediante esta estrategia financiera, se intenta reducir el riesgo de pérdida debido a movimientos desfavorables de los valores de los activos $\mathrm{u}$ operaciones financieras.

Existen dos tipos de coberturas:

1. Cobertura estática: Es cuando se mantiene la misma posición durante todo el horizonte temporal.

2. Cobertura dinámica: Se da cuando la posición varía a medida que cambian el valor del activo y del instrumento de cobertura. Cuando se decide efectuar una estrategia de cobertura, antes de tomar la decisión, debe evaluarse una serie de factores a considerar, entre los que tenemos:

- Establecer el grado de exposición al riesgo que se desea tener en cada momento. Los futuros y las opciones constituyen una herramienta que permite aumentar o reducir el riesgo de una cartera hasta un nivel deseado sin necesidad de modificar la posición mantenida en el mercado de contado.

- Evaluar la factibilidad de cubrirse a través de otros instrumentos analizando si los futuros y las opciones son los más adecuados. Analizar la posibilidad de coberturas naturales en las que el nivel de riesgo se va modificando mediante compras o ventas de la posición mantenida en el mercado de contado.

- Elegir el vencimiento del contrato, ya que el plazo de cobertura puede no coincidir. Normalmente, se utiliza el que tiene una vida superior a la del plazo de cobertura, aunque ello pueda generar problemas de liquidez.

- Es conveniente realizar un análisis de correlación entre los movimientos de los precios en el mercado de contado y de futuros, para apreciar si hay una forma- 
ción de precios eficiente. Si no es así, se puede producir una distorsión en la cobertura.

- Hay que evaluar los costos de la cobertura.

\section{RIESGO DE TIPO DE CAMBIO}

Refleja las variaciones potenciales que se pueden producir en el valor de las posiciones en moneda extranjera por las variaciones de tipo de cambio de contado de la moneda nacional o de una moneda extranjera contra otra.

Las fluctuaciones experimentadas en los tipos de cambio durante los últimos años en los mercados financieros internacionales han convertido a la identificación, medición y gestión de riesgos precedentes de dichas fluctuaciones en un aspecto muy importante en la gestión de la empresa.

\section{Tipo de cambio de equilibrio}

El tipo de cambio es el precio de la divisa extranjera en términos de la moneda nacional. En una economía abierta, el tipo de cambio es uno de los precios más importantes. El tipo de cambio está determinado por las fuerzas de la oferta y de la demanda; por consiguiente, para entender las variaciones en el tipo de cambio, hay que analizar los factores que afectan la oferta y la demanda de divisas.

Entre las principales orígenes de la oferta de divisas tenemos:

- Las exportaciones de bienes y servicios.

- Las remesas de los peruanos que trabajan en el extranjero.

- El ingreso neto de capital extranjero, que incluye la inversión extranjera directa y la inversión financiera.

- La venta de divisas en el mercado por el Banco Central.
La demanda de divisas tiene como sus principales causas:

- Las importaciones de bienes y servicios.

- Las salidas neta de capitales que se producen por la salida de la inversión extranjera en cartera, la inversión de los residentes en el extranjero, el servicio de la deuda externa.

Si la demanda de divisas varía al mismo ritmo que la oferta de divisas, el tipo de cambio permanece constante.

Cuando aumenta la oferta de divisas permaneciendo constante la demanda, el tipo de cambio baja, se produce revaluación o apreciación de la moneda nacional frente a la moneda extranjera.

$\mathrm{Si}$, por el contrario, aumenta la demanda de divisas mientras la oferta permanece constante, la moneda nacional se deprecia o devalúa.

La intervención de la autoridad monetaria (Banco Central de Reserva), al afectar la oferta o la demanda de divisas, puede contrarrestar otros factores que presionan el tipo de cambio al alza o a la baja.

\section{Mercado de divisas}

Es el marco organizacional dentro del cual los bancos, las empresas y las personas compran y venden monedas extranjeras. Una de las funciones del mercado de divisas es determinar los precios de diferentes divisas. El precio de una divisa en términos de otra se llama tipo de cambio.

El mercado de divisas es continuo porque nunca cierra. No hay precio de apertura ni precio de cierre, los tipos de cambio se modifican constantemente.

El mercado de divisas permite transferir fondos (o poder adquisitivo) entre países y ofrece facilidades para la administración de riesgos mediante la cobertura y la especulación. 
Considerando el plazo de entrega de la moneda extranjera, se cuenta con cuatro segmentos en el mercado de divisas:

1. Mercado al contado (spot).

2. Mercado a plazos (forward).

3. Mercado de futuros (future).

4. Mercado de opciones (options).

El tipo de cambio al contado o spot se refiere al precio de una moneda en operaciones con entrega inmediata (en los dos días siguientes a la transacción), mientras que el tipo de cambio a plazos o forward se refiere a operaciones de compra y venta de monedas con entrega aplazada.

En el mercado al contado o spot, el tipo de cambio se fija de manera continua a medida que se van cruzando operaciones.

Las cotizaciones del mercado spot suelen aparecer en pares, con un precio de compra y otro de venta. La diferencia o spread es el beneficio que obtiene el banco o intermediario financiero.

En el mercado a plazos o forwards se establece la entrega en una fecha fijada de antemano de una cantidad de una moneda a cambio de otra cantidad de otra moneda. El tipo de cambio se fija en el momento en el que se formaliza el contrato

Los spreads entre el precio de compra y precio de venta en las operaciones a plazo son mayores cuanto mayor es la volatilidad de la moneda y mayor es la duración del contrato. Las pérdidas o ganancias que se originan en las operaciones a plazo vienen determinadas por la diferencia entre el precio de forward y el precio spot en el momento del vencimiento del contrato.

\section{Determinación del tipo de cambio}

El tipo de cambio en el mercado de divisas se puede obtener a través de cuatro mecanismos o regímenes cambiarios: flotación libre, flotación controlada, mecanismos de banda y tipo de cambio fijo.

La flotación libre implica que el tipo de cambio se determina por la ley de la oferta y la demanda, mientras que en los mecanismos de flotación controlada, el de bandas y en el de tipo fijo, los bancos centrales de los países pueden intervenir de diferentes maneras en el mercado de divisas para modificar el tipo de cambio.

En la figura 4 se muestran los factores fundamentales que determinan el tipo de cambio.

El tipo de cambio de equilibrio es aquel que permite mantener una posición sostenible en la balanza de pagos. Los criterios para establecer un tipo de cambio de equilibrio son diferentes en cada país, y en el mismo país cambian en la medida en que se modifiquen los fundamentos de la economía.

El tipo de cambio de equilibrio las exportaciones de bienes y servicios son exactamente iguales a las importaciones. En el régimen de tipo de cambio flotante, el tipo de cambio de equilibrio se establece de manera automática en el punto donde la oferta es igual a la demanda. En un régimen de tipo de cambio fijo las autoridades monetarias deben calcular el tipo de cambio de equilibrio tomando como base las experiencias del pasado y las proyecciones del comportamiento de los principales rubros de la cuenta corriente. 


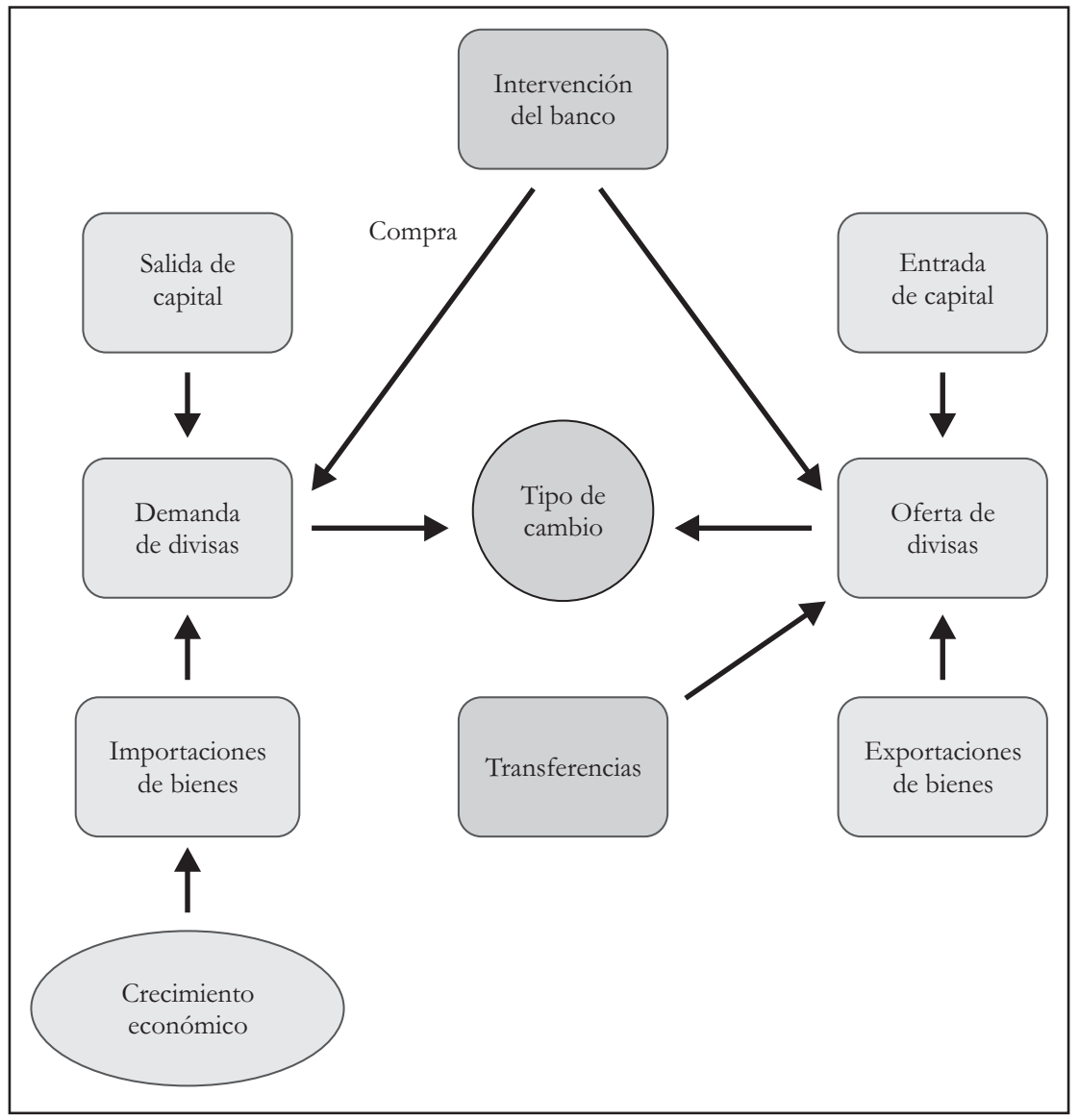

Figura 4. Factores fundamentales que determinan el tipo de cambio. Tomado de Finanzas internacionales de Zbigniew Kozikowski.

\section{TIPOS DE CAMBIO DIRECTOS Y CRUZADOS}

La forma más utilizada de cotizar el tipo de cambio es el llamado términos europeos que viene a ser la cantidad de moneda extranjera necesaria para comprar un dólar estadounidense. El tipo de cambio en el Perú expresado en términos europeos es de $\mathrm{S} / .3 .15$ nuevos soles por dólar.

El tipo de cambio en términos norteamericanos, es la cantidad de dólares necesarios para comprar una unidad de moneda extranjera. Expresado en Estados Unidos de Norteamérica, tenemos que el tipo de cambio del Nuevo Sol se expresa US.

\section{Tipo de cambio directo}

Es el precio de una moneda en términos de otra moneda. El tipo de cambio nuevo sol / USD es la cantidad de nuevos soles que se necesitan para adquirir un dólar:

$$
\text { TC (S/. / US })=2.98 \text {. }
$$

\section{Tipo de cambio cruzado}

Es el precio de una moneda en términos de otra moneda, pero calculada a través de una tercera moneda. El tipo de cambio cruzado nuevo sol / euro a través del dólar se representaría:

$$
\text { TC } \frac{\text { Nuevo sol }}{\text { Euro }}=\text { TC } \frac{\text { Nuevo sol }}{\text { USD }} \times \frac{\text { TC USD }}{\text { Euro }}
$$


Si se requieren $S / .3 .92$ nuevos soles para adquirir un dólar y cada dólar compra 0.7152 euros, el tipo de cambio cruzado nuevo sol / euro será: 3.92/0.7152 = S/.5.48/euro.

\section{Exposición al Riesgo de Tipo de Cambio}

Existen dos clases de exposiciones al riesgo de tipo de cambio: exposiciones contables y exposiciones económicas, que son:

\section{Exposición Contable}

La empresa enfrenta un riesgo de exposición contable cuando una filial opera en otro país, los estados financieros de esa filial van a estar expresados en la moneda de ese país y para efectos de consolidar los estados financieros de la filial con los de la matriz, debe efectuarse un proceso de traslación mostradas en la figura $\mathrm{N} .^{\circ} 5$.

\section{La NIC 21 y la exposición contable}

El objetivo de esta norma contable es pres- cribir cómo se incorporan, en los estados financieros de una entidad, las transacciones en moneda extranjera y los negocios en el extranjero y cómo convertir los estados financieros a la moneda de presentación elegida.

La norma presenta las siguientes definiciones:

- Moneda funcional. Es la moneda del entorno económico principal en el que opera la entidad.

- Moneda extranjera (o divisa). Es cualquier otra distinta de la moneda funcional de la entidad.

- Moneda de presentación. Moneda con que se presentan los estados financieros.

- Partidas monetarias. Son unidades monetarias mantenidas en efectivo, asi como activos y pasivos que se van a recibir o pagar, mediante una cantidad fija o determinable de unidades monetarias.

- Tasa de cambio de contado. Es la tasa de cambio utilizada en las transacciones con entrega inmediata.

- Tasa de cambio de cierre. Es la tasa de cambio de contado existente a la fecha del balance

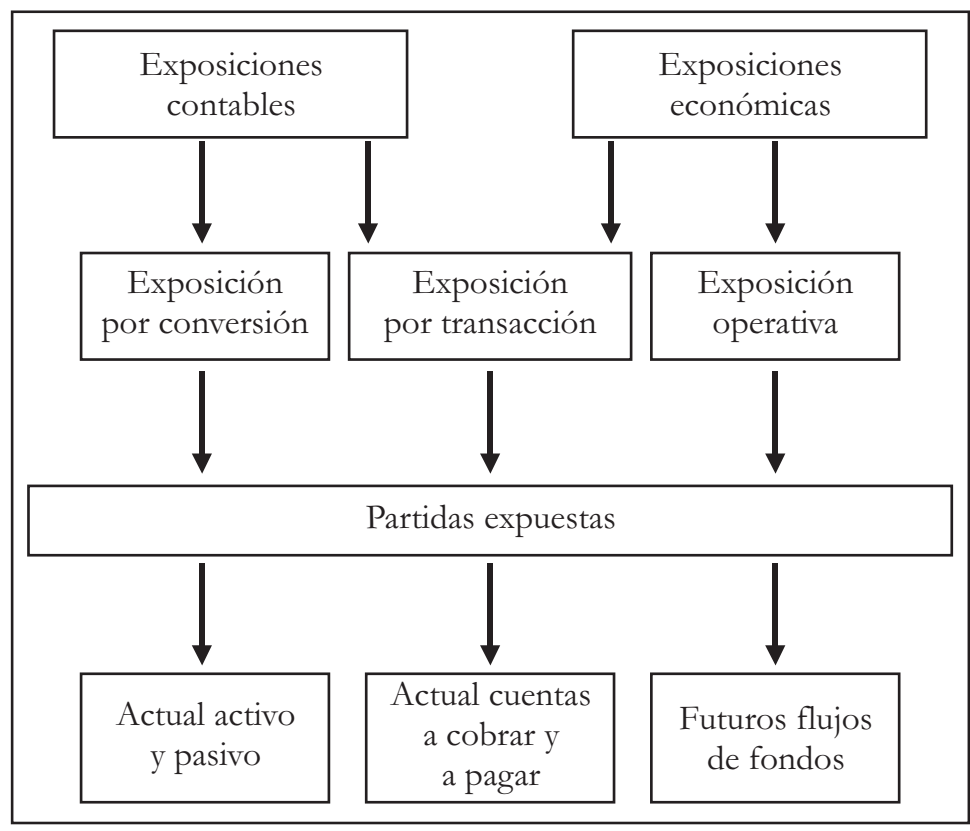

Figura $\mathbf{N}^{\circ}$ 5. Exposiciones a riesgo de tipo de cambio. 
La norma establece en el reconocimiento inicial que:

"Toda transacción en moneda extranjera se registrará en el momento de su reconocimiento inicial, utilizando la moned a funcional mediante la aplicación al importe en moneda extranjera, de la tasa de cambio de contado a la fecha de la transacción entre la moneda funcional y la moneda extranjera".

La presentación de la información financiera en las fechas de los balances posteriores, en cada fecha de balance se tomará en cuenta:

a) Las partidas monetarias en moneda extranjera se convertirán utilizando la tasa de cambio de cierre.

b) Las partidas no monetarias en moneda extranjera, que se midan en términos de costo histórico, se convertirán utilizando la tasa de cambio en la fecha de la transacción; y

c) Las partidas no monetarias que se valoren al valor razonable en una moneda extranjera, se convertirán utilizando las tasas de cambio de la fecha en que se determine este valor razonable.

\section{Reconocimientos de diferencias de cambio}

En la NIC 21 se establece que las diferencias de cambio que surjan al liquidar las partidas monetarias, o al convertir las partidas monetarias a tipos diferentes de los que se utilizaron para su reconocimiento inicial, ya se hayan producido durante el periodo o en estados financieros previos, se reconocerán en los resultados del periodo en el que aparezcan.

La NIC 39 para la aplicación de coberturas en moneda extranjera considera que en una cobertura de flujo de efectivo, las diferencias de cambio de las partidas monetarias que cumplan las condiciones para ser instru- mentos de cobertura, se contabilicen inicialmente en el patrimonio neto, en la medida que esa cobertura sea efectiva.

\section{Exposición por transacción}

Refleja el impacto que puede generar las variaciones del tipo de cambio en el resultado de una transacción efectuada con divisas.

Para poder medir el grado de exposición al riesgo por las transacciones es necesario determinar la posición neta en cada en cada moneda extranjera, para poder explicar esta situación expondremos los siguientes ejemplos. Ejemplo 1. Una empresa tiene la siguiente posición al 31 de diciembre de 2008 :

$\begin{array}{cccc}\text { Partida } & \text { US\$ } & \text { Euro } & \text { Yen } \\ \text { Cuenta por cobrar } & 535,000 & 486,000 & 143.000 \\ \text { Cuentas por pagar } & \underline{243,000} & \underline{598,000} & \underline{260,000} \\ \text { Exposición neta } & 292,000 & (112,000) & (117,000)\end{array}$

La posición en dólares americanos es neta positiva, mientras que en euros y yenes es neta negativa.

\section{Exposición Económica}

La exposición económica se produce al variar los flujos de fondos de la empresa por modificaciones del tipo de cambio, lo que varía el valor de la empresa, cuando este valor se mide aplicando el método de flujo de caja descontado.

\section{Presentacion del Riesgo de Cambio en los Estados Financieros}

La empresa industrial Paramonga presenta en sus notas a los estados financieros al 31 de diciembre de 2008, dentro de riesgo de mercado el riesgo de tipo de cambio: 


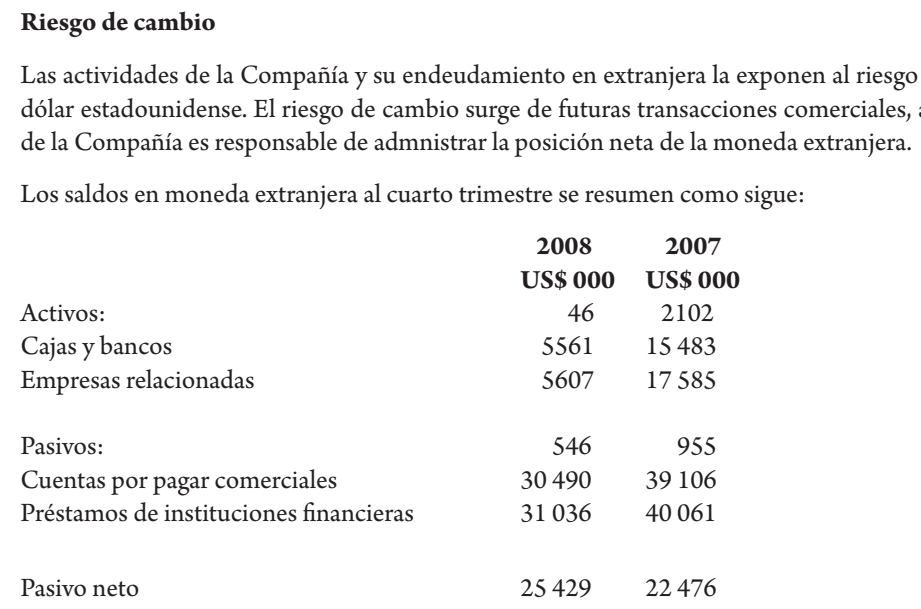
de la Compañía es responsable de admnistrar la posición neta de la moneda extranjera.

Los saldos en moneda extranjera al cuarto trimestre se resumen como sigue:

Activos:

Cajas y bancos

Empresas relacionadas

Pasivos:

Cuentas por pagar comerciales

Préstamos de instituciones financieras

Pasivo neto

$\begin{array}{cc}\mathbf{2 0 0 8} & \mathbf{2 0 0 7} \\ \text { US\$ 000 } & \text { US\$ 000 } \\ 46 & 2102 \\ 5561 & 15483 \\ 5607 & 17585 \\ & \\ 546 & 955 \\ 30490 & 39106 \\ 31036 & 40061 \\ & \\ 25429 & 22476\end{array}$

Las actividades de la Compañía y su endeudamiento en extranjera la exponen al riesgo de fluctuaciones en los tipo de cambio del dólar estadounidense. El riesgo de cambio surge de futuras transacciones comerciales, activos y pasivos reconocidos. La Gerencia

Al 31 de diciembre de 2008, el tipo de cambio utilizado por la Compañía para el registro de los saldos en moneda extranjera ha sido de S/.3.137 y S/. 3.140 por US\$ 1 para los activos y pasivos, respectivamente (S/.2.992 y S/. 2.994 por US\$ 1 para los activos y pasivos, respectivamente, al 31 de diciembre de 2007), los cuales son publicados por la Superintendencia de Banca, Seguros y AFP. Al 31 de diciembre de 2008 y 31 de diciembre de 2007, la Compañía registró ganancias en cambio por S/. 35.5 millones y S/. 15.1 millones y pérdidas en cambio por S/.40,7 millones y S/. 9,1 millones, respectivamente.

\section{GESTIÓN DEL RIESGO DE TIPO DE CAMBIO}

El gestor financiero deberá considerar los siguientes puntos para su toma de decisiones:

1. El tipo de riesgo que se desea cubrir.

2. La cuantificación del riesgo según su posición adoptada (plazos, porcentaje representativo del riesgo ante sus activos, etc.).

3. Delimitación del grado de cobertura (tipo de cobertura).

4. Análisis de los instrumentos financieros derivados disponibles y valorar su aplicación en su empresa.

5. Valorar, finalmente, los gastos de cobertura de cada instrumento, la eficacia, rapidez y precios.

Por lo tanto, cualquier acción del gestor financiero que se traduzca en un descenso del nivel de riesgo total de la empresa, relacionada a una posición presente o futura en los mercados al contado o financieros, se entenderá como una operación de cobertura.

\section{Posición de cambio}

La empresa debe analizar su posición de cambio de Cambio Contable, que es equivalente a la diferencia entre los activos en moneda extranjera y los pasivos en moneda extranjera.

En la figura 6 se presenta la posición monetaria tanto en moneda nacional como en moneda extranjera, para el presente trabajo solo tomaremos la posición monetaria en moneda extranjera que va a reflejar la posición de cambio.

Un valor positivo de la Posición de Cambio Contable implica que la empresa tiene una posición larga en divisas (es decir, presentan activos netos en moneda extranjera). Por otro lado, un valor negativo de la Posición de Cambio Contable significa que la empresa presenta una posición corta en divisas.

En el primer caso, el riesgo de pérdida está determinado por una apreciación cambiaria, mientras que en el segundo caso, las pérdidas se determinan por una depreciación cambiaria. 
EXPOSICIÓN SEGÚN ESTRUCTURA DE BALANCE / ESCENARIOS

CASO 1

Activo

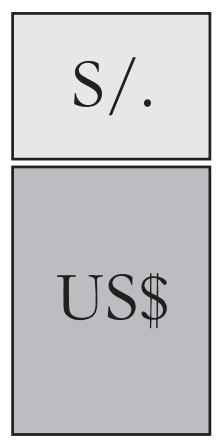

Devaluación MN: Beneficio

Revaluación MN: Pérdida
CASO 2

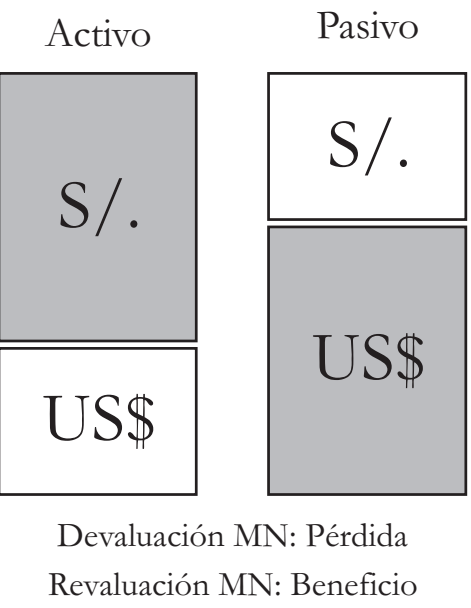

Figura N.o 6. Posición monetaria

\section{Cobertura O’Hedging}

Entenderemos por cobertura O'Hedging a la técnica financiera que intenta reducir el riesgo de pérdida debido a movimientos desfavorables de precios en materia de tipo de interés, tipo de cambio y movimientos de las acciones.

Existen también distintos tipos de cobertura según el punto de vista de la teoría financiera adoptada (Ver cuadro N. ${ }^{0} 1$ ).

\section{Concepto}

Compra de contratos de futuros, para vender después en el mercado al contado.

Venta de contratos para cubrir una postura de compra del mercado de contado.

El valor monetario de las tendencias al contado será cubierto en su totalidad por un valor igual en el mercado de futuros.

Se realiza un valor menor al total de las tendencias al contado.
Es operar sobre una única serie de contratos de futuros (características idénticas).

Implica operar en más de una serie de contratos futuros, ya sean sobre el mismo bien o sobre diferentes bienes.

Es aquella en la cual el bien subyacente y el bien al contado es el mismo.

Es cuando el bien al contado es cubierto con un contrato de futuro cuyo bien subyacente difiere del primero.

Cubre el inventario de un bien, ante la expectativa a la baja de los precios al contado en el futuro. Es una cobertura a corto y completa. "Dado que el operador al desear un bien previamente ya comprado en el mercado al contado, deberá realizar la operación contraria en el mercado de futuro, lo cual supondrá una venta por la cantidad de contratos que iguale el valor total de su posición al contado".

Es la posibilidad de fijar un precio de una forma anticipada, a una transacción que se desea efectuar en el mercado al contado, en 
Cuadro N.o 1. Coberturas

\begin{tabular}{|c|c|}
\hline TIPOS DE COBERTURA & CONCEPTO \\
\hline Cobertura a largo plazo & Compra de contratos de futuros, para vender después en el mercado al contado. \\
\hline Cobertura a corto plazo & Venta de contratos para cubrir una postura de compra del mercado de contado. \\
\hline Cobertura completa & $\begin{array}{l}\text { El valor monetario de las tendencias al contado será cubierto en su totalidad por un } \\
\text { valor igual en el mercado de futuros. }\end{array}$ \\
\hline Cobertura incompleta & Se realiza un valor menor al total de las tendencias al contado. \\
\hline Cobertura simple & Es operar sobre una única serie de contratos de futuros (características idénticas) \\
\hline Cobertura compuesta & $\begin{array}{l}\text { Implica operar en más de una serie de contratos futuros, ya sean sobre el mismo } \\
\text { bien o sobre diferentes bienes. }\end{array}$ \\
\hline Cobertura directa & Es aquella en la cual el bien subyacente y el bien al contado es el mismo. \\
\hline Cobertura cruzada & $\begin{array}{l}\text { Es cuando el bien al contado es cubierto con un contrato de futuro cuyo bien } \\
\text { subyacente difiere del primero. }\end{array}$ \\
\hline $\begin{array}{l}\text { Cobertura como medida } \\
\text { para evitar el riesgo }\end{array}$ & $\begin{array}{l}\text { Cubre el inventario de un bien, ante la expectativa a la baja de los precios al con- } \\
\text { tado en el futuro. Es una cobertura a corto y completa. "Dado que el operador al } \\
\text { desear un bien previamente ya comprado en el mercado al contado, deberá realizar } \\
\text { la operación contraria en el mercado de futuro, lo cual supondrá una venta por la } \\
\text { cantidad de contratos que iguale el valor total de su posición al contado". }\end{array}$ \\
\hline Cobertura anticipada & $\begin{array}{l}\text { Es la posibilidad de fijar un precio de una forma anticipada, a una transacción que } \\
\text { se desea efectuar en el mercado al contado, en un tiempo posterior al que se ha } \\
\text { realizado la cobertura. }\end{array}$ \\
\hline Cobertura operacional & $\begin{array}{l}\text { Es un sustituto temporal de una transacción que se ha planeado realizar, esta co- } \\
\text { bertura en el mercado de futuro será mantenida hasta que la transacción haya sido } \\
\text { efectuada. }\end{array}$ \\
\hline Cobertura selectiva & $\begin{array}{l}\text { Está compuesta por dos posturas, la primera será una postura de cobertura y la } \\
\text { segunda será meramente especulativa. Este tipo de cobertura es, finalmente, una } \\
\text { cobertura incompleta por la parte especulativa que se mantiene a la espera de una } \\
\text { oportunidad de obtener un beneficio especulativo con la posición de mercado. }\end{array}$ \\
\hline Carring - charge hedge & $\begin{array}{l}\text { Esta cobertura es totalmente de tipo arbitrajista ya que "Consiste en la compra } \\
\text { y subsiguiente almacenamiento de un bien al contado, con la consiguiente y si- } \\
\text { multanea venta de contratos de futuro con el único propósito de beneficiarse del } \\
\text { diferencial neto entre el precio al contado y el precio a futuro". }\end{array}$ \\
\hline
\end{tabular}

un tiempo posterior al que se ha realizado la cobertura.

Es un sustituto temporal de una transacción que se ha planeado realizar; esta cobertura, en el mercado de futuro, será mantenida hasta que la transacción haya sido efectuada.
Está compuesta por dos posturas, la primera será una postura de cobertura y la segunda meramente especulativa. Este tipo de cobertura es, finalmente, una cobertura incompleta por la parte especulativa que se mantiene a la espera de una oportunidad de obtener un beneficio especulativo con la posición de mercado. 
Esta cobertura es totalmente de tipo arbitrajista, ya que "Consiste en la compra y subsiguiente almacenamiento de un bien al contado, con la consiguiente y simultánea venta de contratos de futuro con el único propósito de beneficiarse del diferencial neto entre el precio al contado y el precio a futuro".

\section{INSTRUMENTOS DERIVADOS PARA CONTRATOS FORWARDS}

Un contrato forward es un acuerdo entre dos partes. El comprador del contrato (titular) se compromete a comprar ese activo a un precio determinado al cabo de un tiempo (período) determinado de antemano. El titular del contrato tiene, así la obligación de adquirirlo al precio determinado por él.

\section{Características}

No exigen desembolso inicial, pues al vencimiento del contrato hay un solo flujo de dinero a favor del "ganador".

\section{Tipos de Forward}

- Fra

- Fsa

- Forward en divisas

\section{¿Dónde se negocian?}

No es un mercado organizado, como puede ser el de futuros y opciones, sino que se negocian a través de los departamentos de tesorería y divisas de algunas entidades financieras.

Vamos a definir brevemente cada tipo de forward:

Fra. Su finalidad es ofrecer cobertura ante la volatilidad de los tipos de interés.
Fsa Forward Spread Agreement. Es un acuerdo entre dos partes acerca de la diferencia entre los tipos de interés de dos divisas.

Forward de divisas o seguro de cambio. Es un acuerdo entre dos partes en el que se fija el precio, a día de hoy, de una divisa con entrega en el vencimiento.

\section{¿Qué es un Forward de divisas?}

Un Forward de Divisas es un contrato entre dos partes en el que se acuerda la compra venta de moneda extranjera a futuro. Hay que tener en cuenta lo siguiente:

Fecha futura. La fecha en la que las partes realizarán la operación de compra / venta de Dólares bajo las condiciones pactadas.

Posición. Es la posición que cada una de las partes define. Esta puede ser "compradora" o "vendedora".

Monto. Define el importe de la operación denominado en la divisa a transar.

Precio Forward. El precio al cual las partes realizarán la operación pactada.

Liquidación. La forma en la que las partes transferirán los activos en la fecha futura. Existen 2 formas de liquidar estos contratos: por entrega física y por compensación.

\section{Tipos de Forward de divisas}

- Por entrega física (Delivery Forward). Se da el intercambio físico de monedas al vencimiento de la operación, según el tipo de cambio pactado.

- Por compensación (Non Delivery Forward: NDF). Llegada la fecha de vencimiento se compensa el diferencial entre el tipo de cambio futuro pactado y el promedio de compra / venta (tipo de cambio spot). Usualmente, el tipo de cambio usado para la compensación es 
el promedio de compra y venta del día publicado por la SBS.

\section{El Costo de Forward}

El precio Forward se calcula de dos maneras:

- Por diferencial de tasas (Forward Sintético).

- De acuerdo con expectativas de devaluación.

Por diferencial de tasas, el costo de un forward es el resultado del diferencial de las tasas de interés doméstica (S/.) y la tasa de interés de la divisa (US\$)

$$
\text { Diferencial }=\left[\frac{(1+\text { Tasa } M N)}{(1+\text { Tasa } M E)}\right]-1
$$

\section{Cálculo de Forward}

El cálculo del Tipo de Cambio del Forward se realiza a través de la siguiente fórmula:

TC Forward $=$ TC Spot $\mathrm{x} 1+$ Diferencial $(\mathrm{N} / 360)$

- TC Forward. Tipo de cambio al que se contrata el forward.

- TC Spot. Tipo de cambio de la fecha que se contrata el forward.

- Difrencial. El costo de la operación.

- N. Plazo de la operación en número de días.

\section{Cálculo de Forward}

\section{Ejemplo:}

Tipo de cambio Spot: S/. 3.2

Tasa Moneda Nacional: $10 \%$

Tasa Moneda Extranjera: 5\%

Plazo: 180 días

Cálculo Diferencial

$$
\text { Diferencial }=\frac{(1+10 \%)}{(1+5 \%)}-1=4.76 \%
$$

Cálculo Tipo de Cambio Forward

TC Forward $=S / .3 .2 x(1+4.76 \%)^{\wedge}(180 / 360)=S / .3 .275$

\section{Seguro de Cambio - Forward}

Mediante el Forward, se asegura un tipo de cambio para la venta de USD a un precio y momento determinado. Las partes involucradas están obligadas en la fecha de vencimiento a intercambiar los nominales al precio determinado en el forward. No hay derechos sino obligaciones. Este producto permite cubrir totalmente la posición frente a un movimiento bajista del USD, pero no se aprovecha de movimientos alcistas en la cotización del USD. Tanto la duración como el importe del contrato son negociables, ya que se trata de un contrato "hecho a medida" .

Ejemplo: Posición de una empresa que cierra una forward de ventas de USD

$\begin{array}{ll}\text { Vencimiento: } & 3 \text { meses } \\ \text { Spot }(\mathrm{S}): & 3.165 \\ \text { Forward }(\mathrm{F}): & 3.147\end{array}$

\section{Escenarios al final del período de 3 meses}

Si USD $/$ PEN $<3.147 \rightarrow$ Empresa vende los USD a 3.147. Un precio mejor que contado.

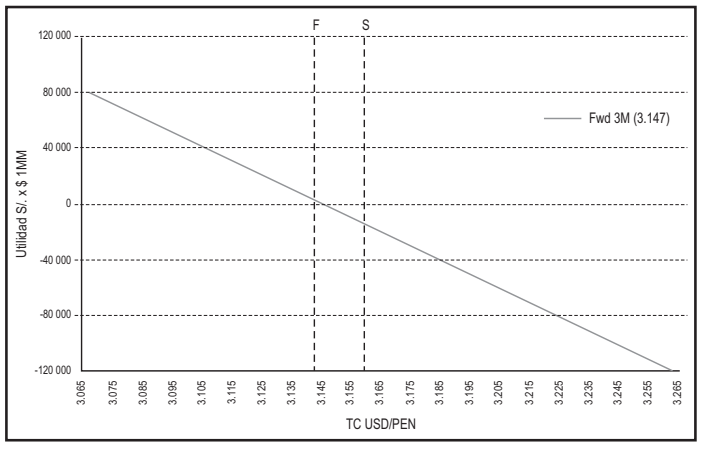

Si USD/PEN > 3.147 $\rightarrow$ Empresa vende los USD a 3.147. Un precio mas bajo que en contado. 


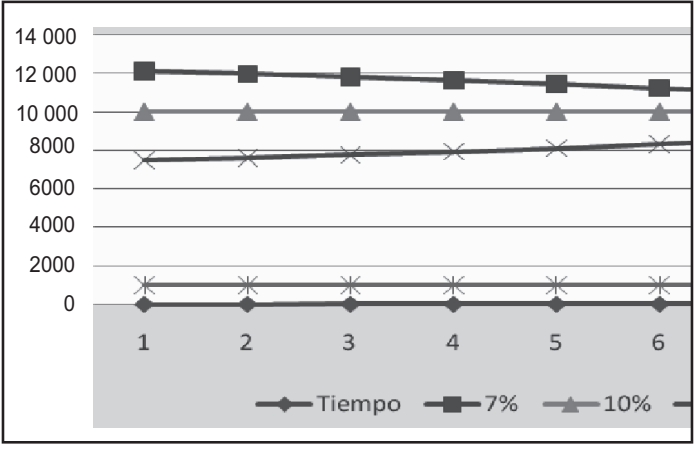

Perfil de la empresa más la posición del subyacente.

\section{CONCLUSIÓN}

Es necesario que en toda empresa se analice e interprete el comportamiento de las finanzas internacionales para poder medir el efecto en su situación económica financiera.
La determinación del tipo de cambio de una moneda está afectado por factores internos y externos.

La empresa debe determinar su posición monetaria en todas las monedas con las que efectúa transacciones y medir el riesgo al que está expuesta, para poder aplicar los mecanismos de cobertura adecuados.

\section{REFERENCIAS BIBLIOGRÁFICAS}

1. Zbigniew Kozikowski Z. McGraw-Hill. Finanzas Internacionales.

2. Ahmad Rahnema Deusto. Finanzas internacionales.

3. Ruy Lama C. Estudios Económicos BCR. Administración del Riesgo Cambiario.

4. Alfonso de Lara Haro. Medición y control de riesgos financieros. Limusa. 